Publisher: CSIRO; Journal: FP:Functional Plant Biology

Article Type: research-article; Volume: ; Issue: ; Article ID: FP13334

DOI: 10.1071/FP13334; TOC Head:

\title{
Leaf shape influences spatial variation in photosynthetic function in Lomatia tinctoria
}

Andrea Leigh ${ }^{\mathrm{A}, \mathrm{D}}$, Ross Hill ${ }^{\mathrm{B}}$ and Marilyn C. Ball ${ }^{\mathrm{C}}$

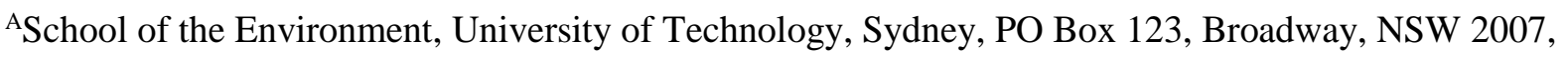
Australia.

${ }^{\mathrm{B}}$ Centre for Marine Bio-Innovation and Sydney Institute of Marine Science, School of Biological, Earth and Environmental Sciences, The University of New South Wales, Sydney, NSW 2052,

Australia.

CPlant Science Division, Research School of Biology, The Australian National University, Canberra, ACT 0200, Australia.

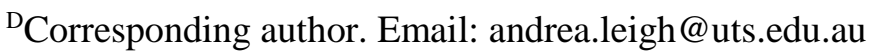

A relationship exists between the two-dimensional shape of leaves and their venation architecture, such that broad or broad-lobed leaves can have leaf tissue far from major veins, potentially creating stronger gradients in water potential - and associated photosynthetic function - than found across narrow counterparts. We examined the spatial patterns of photosynthetic efficiency $\left(\Delta F / F_{\mathrm{m}}{ }^{\prime}\right)$ and non-photochemical quenching (NPQ) in response to increased vapour pressure deficit (VPD) using two morphs of Lomatia tinctoria (Labill.) R.Br: those with broad-lobed and those with narrow-lobed leaves. Stomatal conductance $\left(g_{\mathrm{s}}\right)$, instantaneous water use efficiency (WUE), stomatal and minor veins density also were measured. $\Delta F / F_{\mathrm{m}}{ }^{\prime}$ decreased with stress but was higher and less spatially heterogeneous across broad than narrow lobes. The strongest depression in $\Delta F / F_{\mathrm{m}}{ }^{\prime}$ in broad lobes was at the edges and in narrow lobes, the tips. Non-photochemical quenching was spatially more varied in broad lobes, increasing at the edges and tips. Variation in photosynthetic function could not be explained by $g_{\mathrm{s}}$, WUE or minor vein density, whereas proximity to major veins appeared to mitigate water stress at the tips only for broad lobes. Our findings indicate that the relationship between venation architecture and water delivery alone cannot explain the spatial pattern of photosynthetic function.

Additional keywords: chlorophyll fluorescence, leaf morphology, leaf shape, leaf venation, photoprotection, water stress.

\section{A. Leigh et al.}

Leaf shape influences photosynthetic function

It is not yet known why leaf shape varies so widely among different plant species, but plant biologists suspect one reason might relate to different adaptations for optimal water delivery to and within leaves. This study showed that in response to extreme short-term water stress, photosynthetic function was more spatially uniform in broad-shaped leaves, despite the lower density of water conducting veins to support photosynthesis, relative to narrow-shaped leaves. These findings suggest that the spatial arrangement of veins alone is not responsible for different stress responses in contrasting leaf shapes. 


\section{Introduction}

Leaf shape varies enormously among species but a consensus is yet to be found as to what the functional significance of this variation may be. It is generally agreed, however, that a relationship exists between leaf shape and water delivery (Sisó et al. 2001; Zwieniecki et al. 2004b; Nicotra et al. 2011). This relationship results from the highly ramified nature of veins in eudicot angiosperm leaves and the hierarchical ordering of major to minor veins throughout the leaf lamina. Because hydraulic resistance increases as conduit diameter decreases, resistance to water flow will increase from the largest central veins to the small distal veins. The extra vascular pathway from the point of leaving the veins to the site of evaporation from stomata may present a still greater resistance (Cochard et al. 2004; Brodribb et al. 2007). Due to the ever-decreasing size of veins as they ramify, leaf laminae that are narrow or deeply lobed potentially have a greater proportion of mesophyll tissue close to a major vein than broad or broad-lobed leaves. This relationship has been said to result in narrow-lobed leaves receiving a more reliable supply of water across their laminae (low leaf hydraulic resistance) than broad-lobed leaves within a given species or genus (Sisó et al. 2001; Zwieniecki et al. 2002; Sack et al. 2005).

During drought stress, major veins can be less vulnerable to hydraulic dysfunction than minor veins, that latter of which has a greater likelihood of xylem cell collapse due to more negative water potentials and weaker structural reinforcement (Blackman et al. 2010). The importance of major veins in maintaining leaf hydraulic conductance under drought stress is said to vary with leaf size, with small leaves having a higher density of major veins and associated lower hydraulic vulnerability (higher desiccation tolerance) (Scoffoni et al. 2011). Heterogeneous water delivery through spatial variation in conduit size in turn may influence variation in localised photosynthetic function. Comparing two Australian Acacia spp. following a drought event, maximum photosynthetic efficiency - and subsequent recovery - was reduced in the species with low major nerve (vein equivalent in leaf-like phyllodes) density in its phyllodes, relative to the species with a high density of major nerves (Sommerville et al. 2010). These authors found that the density of minor nerves made no difference to either reduction of photosynthetic efficiency or the speed of recovery to maximum photosynthetic efficiency. This finding supports the importance of major conduits in maintaining hydraulic supply to photosynthetic tissue during periods of drought.

From a leaf's perspective, water stress can occur via disruptions not only to supply, e.g. reduced soil water potential, but also demand, e.g. increased vapour pressure deficit (VPD). Although the former can occur over a period of relatively slow soil drying, such as days or longer, changes in VPD can occur more rapidly, for example, rising from 1 to $4 \mathrm{kPa}$ during an afternoon in a treefall gap (Meinzer et al. 1995). Increased VPD can lead to reduced stomatal conductance at the whole-leaf level (Tinoco-Ojanguren and Pearcy 1993; lio et al. 2004), whereas at the subleaf level, this reduction may not be uniform, resulting in spatial patchiness in stomatal conductance (Cardon et al. 1994). 
Publisher: CSIRO; Journal: FP:Functional Plant Biology

Article Type: research-article; Volume: ; Issue: ; Article ID: FP13334

DOI: 10.1071/FP13334; TOC Head:

Stomatal closure is thought to occur in response to reduced humidity at the leaf surface, although the extent to which closure occurs appears to be mediated by xylem water potential (Buckley and Mott 2000). Spatially patchy stomatal conductance in turn leads to spatially patchy photosynthetic activity through $\mathrm{CO}_{2}$ starvation to the photosynthetic apparatus (Cardon et al. 1994). Thus, water stress can compromise photosynthetic function in leaves both through restriction of water delivery from minor veins and via VPD-related stomatal closure.

Spatial variation in photosynthetic activity can be visualised using chlorophyll fluorescence imagery (e.g. Siebke and Weis 1995; Marenco et al. 2006; Sommerville et al. 2010), making it possible to compare the response of leaves subject to short-term stress. Compromised photosynthetic function is indicated by a drop in effective quantum yield $\left(\Delta F / F_{\mathrm{m}}{ }^{\prime}\right)$, where PSII becomes less able to process incoming energy and is vulnerable to damage, often caused by the formation of reactive oxygen species. In response to photosynthetic stressors, photoprotective processes are activated to divert excess light energy away from PSII by dissipating the energy as heat. This non-photochemical quenching (NPQ) of excess energy is most commonly attributed to the xanthophyll cycle, through the production of the photoprotective pigment, zeaxanthin, triggered by an increased proton gradient across the thylakoid membrane of the chloroplast. Although NPQ usually is associated with high light exposure, even under subsaturating light conditions the process can be triggered in response to other causes of reduced photosynthetic energy conversion, such as water stress (Demmig et al. 1988).

When a leaf is subjected to short-term localised water stress imposed by a sharp increase in VPD, we might expect that areas of the leaf lamina closest to major veins will show smaller reductions in photosynthetic efficiency and higher rates of photoprotection than areas further from major veins. We investigated this question in Lomatia tinctoria (Labill.) R.Br., a species with lobed leaves, where the extent of leaf lobing and the width of lobes differ among individual plants. The two extreme morphs shallowly-incised, broad-lobed leaves and deeply-incised narrow-lobed leaves - provide an opportunity for comparison of spatial variation in photosynthetic activity within a single species. Because of the higher ratio of major vein to leaf tissue on the two-dimensional plane of narrow-lobed leaves, our hypothesis was that under conditions of VPD-stress, these leaves would maintain higher $\Delta$ $F / F_{\mathrm{m}}{ }^{\prime}$ (or would have a less pronounced drop in $\Delta F / F_{\mathrm{m}}{ }^{\prime}$ ) than the broad-lobed leaves. For the same reason, our expectation was that narrow lobes would be better able to support photoprotective processes than broad lobes and therefore would exhibit higher NPQ in response to a decrease in $\Delta$ $F / F_{\mathrm{m}}$ '. Given that broad lobes have a larger expanse of tissue away from major water conduits, we also predicted a greater degree of spatial variation in chlorophyll fluorescence across the laminae of broad lobes than across narrow lobes. 


\section{Methods}

Plant specimens

Lomatia tinctoria (Labill.) R.Br. is a small to medium understorey shrub endemic to Tasmania, Australia, belonging to the Gondwanan plant family, Proteaceae. The leaves of this species display a range of shapes and, although leaf shape can vary somewhat within an individual plant, the two extreme morphs, narrow-lobed and broad-lobed leaves (Fig. 1), generally are not found together on one plant. These two morphs have contrasting yet overlapping distributional patterns. The broadlobed morph grows only on the Tasman Peninsula on the South East Cape, restricted to a few coastal populations at Cape Pillar and Cape Huay, receiving an average annual rainfall of $800 \mathrm{~mm}$. The narrow-lobed morph can be found throughout the species' geographical distribution across most of Tasmania, encompassing a much wider variation in annual rainfall, i.e. 500-2500 mm (G Jordan, pers. comm.). Where the two morphs co-exist on the Tasman Peninsula, they grow side-by-side under similar conditions in the understorey of tall open eucalypt forest. This neighbouring growth of discrete morphs is indicative of a genetic basis for a fixed shape rather than environmentally-driven shape plasticity.

Experimental L. tinctoria plants were grown from cuttings taken from the Tasman Peninsula and kept at the Australian National University glasshouse facility outdoors under shade cloth, supplied with low-phosphorus Australian native plant fertiliser. Plants were used for experiments no less than one year after cuttings were potted and when they possessed abundant, healthy foliage. Plants were well watered throughout the experimental period. Approximately $12 \mathrm{~h}$ before laboratory measurements, an individual plant was moved to the laboratory and watered to allow time to adjust to ambient laboratory conditions.

\section{Leaf anatomy}

To test the hypothesis that proximity of tissue to a major vein is more important than minor vein density to physiological function, the density of minor veins proximal and distal to major veins was investigated. Five leaves from each of five plants for each of the two leaf morphs ( 25 narrow- and 25 broad-lobed leaves) were collected and stored in formalin aceto-alcohol for several days before being transferred to $70 \%$ ethanol. Samples were washed before making transverse sections along the length of a leaf lobe by removing the upper epidermis and palisade mesophyll. Sections were then bleached in sodium hyperchlorite warmed over a heating element for 10-20 min and rinsed thoroughly before placing on a microscope side and removing the lower epidermis to fully reveal the vein network. Each section was stained in situ on the slide with Toluidine blue, then dried and mounted with DPX slide mountant for viewing at $\times 100$ magnification using a compound microscope (Olympus BX-50) mounted with a high-resolution digital camera (DFC-280, Leica Microsystems, Wetzlar, Germany). For each of the 50 sectioned leaf lobes, vein density was quantified at five locations (avoiding the mid-rib and first-order veins): the base, centre and tip of the lobe and the left- and right-hand edges, 
Publisher: CSIRO; Journal: FP:Functional Plant Biology

Article Type: research-article; Volume: ; Issue: ; Article ID: FP13334

DOI: 10.1071/FP13334; TOC Head:

just in from the leaf margin. At five replicate points at each location, the largest areole within the minor vein network was identified and the radius of the largest circle that could be drawn within this areole was measured using the Leica Image Manager 500 software (Fig. 2). The average of this radius at each location, herewith referred to as the average vein distance, was deemed to be inversely proportional to vein density.

Stomatal density was measured to determine whether the spatial arrangement of stomata - and therefore the opportunity for stomatal conductance $\left(g_{s}\right)$ to vary spatially - influenced the physiological response (Zhang et al. 2002). The density of stomata (number of stomata $\mathrm{mm}^{-2}$ ) was measured on the lower epidermis of the transverse sections described above and at the same locations on the lamina as for average vein distance. Photographic images of these locations were made, from which stomatal density was calculated.

For both average vein distance and stomatal density, a small number of the target replicates could not be measured because the tissue was destroyed during handling. The final number of vein distance measurements was 749 (347 narrow, 404 broad) and the final number of stomatal density measurements was 1176 (576 narrow, 600 broad). Measurements for each edge were averaged to give a single edge value and replicates were averaged to provide a value for each replicate plant.

\section{Stress and fluorescence imaging}

Four plants of the narrow-lobed and four of the broad-lobed morphs were used for stress treatments. Measurements were conducted on leaves whilst still attached to the plant under laboratory conditions, at a temperature of $22^{\circ} \mathrm{C}$. For each measurement, a portion of an attached leaf was sealed in an opentopped cuvette of an infrared gas analyser (IRGA, Li-Cor 6400, Li-Cor, Lincoln, NE, USA). As our intent was to detect water stress with fluorescence imaging, we minimised electron flow to acceptors other than $\mathrm{CO}_{2}$ by supplying $2 \%$ oxygen only, which reduces photorespiration. Under these conditions, a decreased intercellular $\mathrm{CO}_{2}$ concentration reduces the available electron acceptors for the photosynthetic electron transport, providing a more clearly visible chlorophyll fluorescence signal than under ambient oxygen. Air was supplied via the IRGA air intake, which was connected to a nitrogen gas supply through tubing run via an aerated water tank with an over-pressure outlet. As $L$. tinctoria is an understorey plant and here grown under shade cloth, it was important to not supply excess light that might cause high non-photochemical quenching before water stress was applied. A series of light response curves was therefore conducted using the IRGA, several days before commencing experiments on five randomly selected plants. The average light level sufficient to stimulate strong photosynthesis without strong non-photochemical quenching (i.e. just beyond the steepest part of the photosynthetic response curve) was $365 \mu \mathrm{mol} \mathrm{m}^{-2} \mathrm{~s}^{-1}$ and this light level was supplied throughout measurements. 
Publisher: CSIRO; Journal: FP:Functional Plant Biology

Article Type: research-article; Volume: ; Issue: ; Article ID: FP13334

DOI: 10.1071/FP13334; TOC Head:

At the beginning of each measurement, while steady-state photosynthesis of the leaf was attained, the block temperature of the IRGA cuvette was set to $25^{\circ} \mathrm{C}$, with air and leaf temperatures remaining within $1.5^{\circ} \mathrm{C}$ of this value. Relative humidity in the cuvette was maintained at $\sim 50 \%$, with a VPD of $\sim 1.5 \mathrm{kPa}$. When steady-state photosynthesis was achieved, i.e. 10-15 min, the VPD-stress treatment was applied and run for $40 \mathrm{~min}$. Initially, a sharp increase in VPD was attempted by scrubbing the incoming air (passing it through granulated gypsum desiccant in the IRGA) before delivering it to the leaf in the cuvette. However, using this method alone, it was difficult to reduce relative humidity sufficiently to increase VPD to the desired level (3-4 kPa, Meinzer et al. 1995). Therefore, the block temperature was also increased, raising air temperature in the cuvette to $40^{\circ} \mathrm{C}$, which had the effect of increasing VPD to $\sim 3.5 \mathrm{kPa}$. The decision to increase VPD in this way was justified for two reasons. First, reduction of stomatal aperture is known to be more responsive to increased VPD than to increased air temperature (Barradas et al. 1994; Iio et al. 2004). Second, when the block temperature was raised in preliminary trials, leaf temperature always remained at least $10^{\circ} \mathrm{C}$ cooler than air temperature, rising to between $27^{\circ} \mathrm{C}$ and $30^{\circ} \mathrm{C}$. The relatively cooler leaf temperatures were presumably the result of latent heat loss via continued transpiration during VPD-stress treatments, with $g_{\mathrm{s}}$ ranging from 0.02 to $0.1 \mathrm{~mol} \mathrm{H}_{2} \mathrm{O} \mathrm{m}^{-2} \mathrm{~s}^{-1}$. Thus it was deemed that temperature, light and soil water stress were minimal during these treatments and localised VPD increase was the principle cause of stress to leaves in the cuvette.

To minimise the influence of leaf size on leaf temperature through effects of boundary layer conductance on convection, air flow in the IRGA cuvette was set at $500 \mu \mathrm{mol} \mathrm{s}^{-1}$ to increase forced convection across the laminae. After measurements, leaf temperatures during the VPD-stress period were compared for each morph. Additionally, to investigate the extent to which the two leaf morphs varied in their rate of water loss during stress treatments, $g_{\mathrm{s}}$ and instantaneous water use efficiency (WUE: photosynthetic rate/transpiration rate) were compared. Two values for each of the above three variables were calculated: the onset (the average of the first three IRGA readings logged $5 \mathrm{~min}$ apart) and the end (last three readings) of the period from when VPD rose to $3.0 \mathrm{kPa}$ to the conclusion of measurements.

The variation in chlorophyll fluorescence across the lamina was imaged before and during the 40 min VPD-stress treatment using an Imaging-PAM chlorophyll fluorometer (Heinz Walz GmbH, Effeltrich, Bavaria, Germany) mounted above the leaf in the IRGA cuvette (Fig. 3). Maximum quantum yield $\left(F_{\mathrm{v}} / F_{\mathrm{m}}\right)$ was determined at the beginning of each measurement after 30 min of darkadaptation $\left(\mathrm{T}_{\text {dark }}\right)$. Effective quantum yield $\left(\Delta F / F_{\mathrm{m}}{ }^{\prime}\right)$ and non-photochemical quenching (NPQ: $\left(F_{\mathrm{m}}-\right.$ $\left.F_{\mathrm{m}}{ }^{\prime}\right) / F_{\mathrm{m}}{ }^{\prime}$ ) were determined just before the VPD-stress treatments, following light exposure for at least $10 \mathrm{~min}$ (T0 $\mathrm{L}_{\text {ight }}$ ) and again at 20 and $40 \mathrm{~min}$ after the VPD-stress treatment commenced (T20 and T40 respectively), during which time leaves remained illuminated. To analyse the fluorescence images, three leaf lobes were selected for each plant to obtain an average response for each plant. On each 
Publisher: CSIRO; Journal: FP:Functional Plant Biology

Article Type: research-article; Volume: ; Issue: ; Article ID: FP13334

DOI: 10.1071/FP13334; TOC Head:

lobe, rectangular areas of interest (AOI), $\sim 0.2 \mathrm{~mm}^{2}$ and $2.0 \mathrm{~mm}^{2}$ for narrow and broad lobes, respectively, were drawn using the Walz software, ImagingWin (ver. 2.40b). These AOI were drawn in the same locations as for anatomy, i.e. the tip, edges, centre and base of the lobes. Because some leaves moved very slightly as they became drier during measurements, care was taken with image analyses to place the AOI at the same point on the leaf lamina for measurements at each time point. Values for each AOI were averaged to give a measurement for each position on each leaf lobe replicate.

\section{Statistical analyses}

Two-factor ANOVAs with Tukey's HSD post hoc tests were used to detect variation in the anatomical variables, average vein distance and stomatal density, with position on the lamina (tip, edge, centre and base of lobes) and leaf morph (narrow and broad) as fixed factors. Data for stomatal density were log-transformed to meet assumptions of normality. Two-factor ANOVAs also were used to detect differences in $F_{\mathrm{v}} / F_{\mathrm{m}}$ among positions on the lamina and between morphs.

We performed repeated-measures ANOVAs to investigate differences in leaf temperature, $g_{\mathrm{s}}$ and WUE between the two leaf morphs, with time as the second factor to account for any change in these variables from the onset to the end of VPD-stress. Repeated-measures ANOVAs also were used to examine differences between leaf morphs in $\Delta F / F_{\mathrm{m}}{ }^{\prime}$ and $\mathrm{NPQ}$, with measurement time (pre-stress, during and at the end of stress treatments: $\mathrm{T} 0 \mathrm{~L}_{\mathrm{ight}}, \mathrm{T} 20$ and $\mathrm{T} 40$ respectively) and morph as factors. To determine how variation among positions on the lamina differed between morphs, analyses included measurement time and position as within-subject factors and morph as the between-subject factor. Data for $\Delta F / F_{\mathrm{m}}{ }^{\prime}$ were arcsine transformed, NPQ data were log-transformed. Where Mauchly's assumption of sphericity was not met, Greenhouse-Geisser tests were used. Because a significant interaction between position and morph was found for the $\Delta F / F_{\mathrm{m}}{ }^{\prime}$ analysis, two-factor ANOVAs were then performed on each morph separately to determine the nature of the response for broad $v$. narrow lobes. Statistical analyses were performed using IBM SPSS (ver. 19 and ver. 22).

\section{Results}

\section{Leaf anatomy}

When comparing vein density between leaf morphs, broad lobes had a significantly higher vein distance (lower vein density) than narrow lobes overall (Table 1); however, this difference was not significant at every position on the lamina. Vein distance at the centre and base did not differ significantly between the two leaf morphs, whereas the tips and edges of narrow lobes had a significantly smaller vein distance than at the same locations on broad lobes (Table 1; Fig. 4a). When examining spatial variation within leaf laminae, we found a significantly smaller vein distance at the tips than the centre and base of the lobes, whereas the tips and edges did not significantly differ from 
Publisher: CSIRO; Journal: FP:Functional Plant Biology

Article Type: research-article; Volume: ; Issue: ; Article ID: FP13334

DOI: 10.1071/FP13334; TOC Head:

one another (Table 1; Fig. 4a). No significant interactions between the effects of leaf morph and position on vein distance were detected $(P=0.062)$.

Stomatal density did not differ between narrow and broad lobes overall, nor when comparing analogous locations on the leaf lamina (Table 1; Fig. 4b). Similarly, when comparing spatial variation within leaf morphs, stomatal density did not significantly vary across the lamina of either narrow or broad lobes (Table 1; Fig. 4b).

\section{Physiological response to VPD-stress}

In response to stress, both leaf morphs experienced a marked decrease in quantum yield and increase in non-photochemical quenching (Tables 2, 3; Figs 3, 5). Prior to stress treatments, maximum quantum yield $\left(F_{\mathrm{v}} / F_{\mathrm{m}}\right.$, measured on dark adapted leaves, $\left.\mathrm{T}_{\text {dark }}\right)$ was greater in narrow than broad lobes (Table 1). After light exposure (T0 $\mathrm{L}_{\text {ight }}, \mathrm{T} 20$ and $\left.\mathrm{T} 40\right), \Delta F / F_{\mathrm{m}}{ }^{\prime}$ was significantly higher in broad than narrow lobes overall, i.e. when position on the lamina was accounted for (repeated-measures ANOVA: $\mathrm{F}_{(1,15)}=31.26, P<0.000$; Fig. $\left.5 a\right)$. The reduced photosynthetic efficiency in narrow lobes was accompanied by greater levels of NPQ than broad lobes but this difference was not significant $\left(\mathrm{F}_{(1,15)}=4.49, P=0.051\right.$; Fig. $\left.5 b\right)$.

Accounting for repeated-measures through time, significant spatial variation among positions on the lamina was found in both $\Delta F / F_{\mathrm{m}}{ }^{\prime}$ and NPQ (Table 2). For $\Delta F / F_{\mathrm{m}}{ }^{\prime}$, a significant interaction between position and morph also was found, indicating that the nature of spatial variation in effective quantum yield differed between morphs (Table 2). Variation in $\Delta F / F_{\mathrm{m}}{ }^{\prime}$ was greater across narrow lobes, driven by a lower yield at the lobe tips than the edge, centre or base, while broad morphs showed a slight difference in yield between the edge and base of lobes (Table 3). In contrast, spatial variation in NPQ only was significant in broad lobes, with the tips having a stronger photoprotective response than the centre or base of lobes and the edges also having a stronger response than the base (Table 3). Although marked spatial variation in NPQ was evident in narrow lobes, this was not significant.

From the onset to the end of VPD-stress treatments, a slight, but non-significant, increase in leaf temperature was observed and leaf temperature did not differ between morphs (Table 4). The equivalent leaf temperatures indicate that if differential boundary layer effects between morphs were present in the cuvette, these were minimal. Similarly, a non-significant decrease in $g_{\mathrm{s}}$ and WUE occurred in response to VPD-stress and the two morphs did not significantly differ in either variable overall (Table 4).

\section{Discussion}

We sought to determine whether a functional relationship existed between leaf shape and photosynthetic performance in broad-lobed vs narrow-lobed leaf morphs of L. tinctoria. In particular, 
Publisher: CSIRO; Journal: FP:Functional Plant Biology

Article Type: research-article; Volume: ; Issue: ; Article ID: FP13334

DOI: 10.1071/FP13334; TOC Head:

we predicted that in response to localised water stress, broad lobes would show a more marked spatial variation in chlorophyll fluorescence across their laminae than narrow lobes. However, we found $\Delta F / F_{\mathrm{m}}{ }^{\prime}$ to be higher on average and less spatially variable in broad lobes than narrow lobes. In both leaf types, spatial heterogeneity in $\Delta F / F_{\mathrm{m}}{ }^{\prime}$ was driven by particularly low values at certain regions on the lobe (for broad lobes, the edges; for narrow lobes, the tips); however, such spatial extremes were less marked in broad lobes, which could explain why they maintained higher overall photosynthetic efficiency than narrow lobes. Consistent with expectations though, broad lobes did show greater spatial variation in NPQ than narrow lobes.

The observed spatial patterning in chlorophyll fluorescence can be related to spatial variation in water stress within the leaf laminae. Spatial patchiness in photosynthetic activity is known to correspond to low stomatal conductance (Marenco et al. 2006). In particular, increased NPQ at a given region on a leaf blade corresponds closely to a decline in stomatal conductance at the same region (Omasa and Takayama 2003). In the current study, the localised depression in $\Delta F / F_{\mathrm{m}}{ }^{\prime}$ and increased NPQ may have represented a localised drop in $g_{\mathrm{s}}$ at those regions. Stomatal density can mediate $g_{\text {s }}$ in conjunction with stomatal aperture (Zhang et al. 2002). We do not have an estimate of stomatal aperture but we found stomatal density to be remarkably invariant, both across leaf lobes and between the leaf morphs. If localised stomatal closure occurred, it is likely to be related to reduced water supply or increased demand for water at those regions on the laminae.

In broad lobes, the strongest depression in $\Delta F / F_{\mathrm{m}}{ }^{\prime}$ was apparent at the lobe edges, matched by a strong photoprotective response at the edges and also the tips. Photosynthetic tissue at the edges of broad lobes is proximally supplied by water via the minor vein network, which was relatively sparse in broad lobe edges, potentially increasing the water demand per unit vein length. Under water stress, a low water potential in these minor veins could lead to hydraulic dysfunction (Brodribb and Holbrook 2005; Blackman et al. 2010), reducing the network's capacity to hydrate the surrounding leaf tissue. This localised stress could result in a decrease in photosynthetic efficiency, triggering the observed photoprotective response at the edges. At broad lobe tips, vein density was similar to that of the edges but, unlike the edges, the tips were supplied additionally by a major vein. This difference in water supply between the edges and tips could explain why the latter did not experience a marked drop in $\Delta F / F_{\mathrm{m}}{ }^{\prime}$ in broad lobes and supports previous findings of the comparatively limited ability of minor conduits to supply localised photosynthetic processes when distant from major conduits (Sommerville et al. 2010, 2012).

For narrow-lobed leaves, the observed spatial patterning in physiological response again may be due to varying water supply; however, due to the more lanceolate shape of these lobes, this localised effect appears to be manifest differently in the narrow morph. By far the weakest $\Delta F / F_{\mathrm{m}}$ ' in narrow lobes was evident at the tips, which probably represented a water stress response, as with broad lobes. 
Publisher: CSIRO; Journal: FP:Functional Plant Biology

Article Type: research-article; Volume: ; Issue: ; Article ID: FP13334

DOI: 10.1071/FP13334; TOC Head:

Yet in narrow lobes, this sharp depression in photosynthetic efficiency was met with a relatively weak photoprotective response at tips, compared with other regions on the lobe. At a certain level of waterstress, NPQ can mitigate against associated damage of photosynthetic tissue but inadequate hydration of that tissue also can compromise photoprotective processes (Deltoro et al. 1998; Csintalan et al. 1999). The sharp decrease in photosynthetic efficiency at the tips of narrow lobes in this study may have represented localised water stress severe enough to impair photoprotective function. The strong stress response at the narrow lobe tips was apparently in spite of a correspondingly higher minor vein density than more proximal regions on the lamina, again suggesting that minor conduits in this species do not play a strong role in mitigating short-term water stress. In contrast, given that the tips of both narrow and broad lobes were located proximal to the mid-vein of the lobe, why did we find a stronger stress response at the tips of narrow lobes than broad lobes?

Notwithstanding the importance of major veins in hydrating leaf tissue, a high proportion of major veins per area of leaf does not necessarily reduce overall leaf hydraulic resistance (Sack and Frole 2006). Gradients of resistance occur within leaves, indeed within major veins. Consider the shape of L. tinctoria leaf lobes in terms of the requirement of their primary veins to deliver water along their length to surrounding tissue. For single-vein leaves of broader shapes, conceptually close to a broad lobe of a L. tinctoria leaf, optimal delivery of water to all parts of the lamina requires a primary vein with low radial resistance to water flow and equally low resistance within the surrounding mesophyll tissue (Zwieniecki et al. 2004a). Low hydraulic resistance in regions outside the xylem can be facilitated by a high ratio of spongy to palisade mesophyll tissue (Sack and Frole 2006). Anatomical investigation of the leaves of potted L. tinctoria plants grown in Tasmania (for an unrelated study) found the spongy : pallisade ratio of broad-lobed leaves to be significantly greater than that of narrowlobed leaves (W Ren et al., unpubl. data). A low mesophyll resistance and associated uniform water flow in broad-lobed leaves would contribute to the relatively more spatially homogenous photosynthetic activity observed in our study. In contrast with broad leaf shapes, optimal water delivery along a narrow, needle-like leaf requires high resistance to radial flow in favour of low axial resistance, minimising the pressure drop that can result in dehydration at the leaf tip (Zwieniecki et al. 2004a, 2006). Unlike in needle leaves, however, radial 'leakage' from the major veins in leaves with net-like venation occurs primarily through minor vein connections, with the mesophyll being the source of radial leakage from minor veins (Zwieniecki et al. 2002). Radial flow from the major vein of narrow-lobed L. tinctoria leaves would need to be sufficient to supply the particularly densely spaced minor veins along the lobe edges. A significant increase in evaporative demand imposed by high VPD would create a strong tension in the xylem sap of the major vein, resulting in a steep gradient in water potential between the base and tip of narrow lobes, followed by stomatal closure at the tips. 
Publisher: CSIRO; Journal: FP:Functional Plant Biology

Article Type: research-article; Volume: ; Issue: ; Article ID: FP13334

DOI: 10.1071/FP13334; TOC Head:

In terms of evolutionary adaptation, it is unclear why the two morphs should differ in their structure-function relationships. If the heightened photosynthetic stress response at the tips of narrowlobed leaves does indeed represent suboptimal water delivery, it is difficult to see how this would assist function in the dry sclerophyll regions of this morph's distribution, where they could experience moderate to high VPD. Nonetheless, reduced hydraulic supply to the lobe tips may not represent a long-term problem if this was the result of xylem collapse, which appears to be rapidly reversible, rather than cavitation, which may not be (Brodribb and Cochard 2009). Blackman et al. (2010, 2012) found leaves of the narrow-lobed L. tinctoria morph to have a $25 \%$ lower vulnerability to xylem cavitation than those of its congeneric rainforest relative (L. polymorpha). The former also were found to have a relatively high safety margin (almost $1 \mathrm{MPa}$ ), indicating a relatively strong capacity to maintain photosynthetic activity under increasingly negative xylem tension before experiencing xylem collapse (Blackman et al. 2010). The risk of xylem dysfunction (beginning at the lobe tips) would be the cost to such a strategy but if it caused reversible xylem collapse, rather than cavitation, it would allow this morph to maintain growth under dry conditions. The desiccation tolerance of the broad-lobed L. tinctoria morph is not known but its restricted distribution to a region receiving higher rainfall than the drier regions into which the narrow-lobed morph can extend suggests that it may be more vulnerable to drought than the latter. The region where these two morphs co-exist on the South East Tasman Cape is a site known for endemic and/or relictual plant species (G Jordan, pers. comm.). The broad-lobed morph therefore could represent a genetically distinct variant of L. tinctoria more suited to a cooler, wetter environment that once prevailed in Tasmania. Research into the desiccation tolerance of these two morphs would help to address this idea.

\section{Conclusion}

Our aim was to test the hypothesis that the relationship between leaf venation and leaf shape on a twodimensional plane would result in a more contrasting spatial pattern of physiological stress response across broad-lobed leaves than narrow lobed leaves of L. tintoria. In response to a sharp increase in localised VPD, we found photosynthetic efficiency to be more spatially heterogeneous across narrow lobes than broad lobes. In particular, the strongest depression in $\Delta F / F_{\mathrm{m}}$ ' in broad lobes was at the edges of lobes, whereas in narrow lobes an extreme drop in $\Delta F / F_{\mathrm{m}}{ }^{\prime}$ was seen the tips. The photoprotective response in narrow lobes was weak relative to that in broad lobes, where NPQ increased at both the lobe edges and tips. These differences were in spite of similar $g_{\mathrm{s}}$ for each morph and similar stomatal density, both across leaves and between morphs. A higher minor vein density at the edges and tips of narrow lobes than broad lobes apparently did not greatly assist in maintaining photosynthetic function at these regions during VPD stress. In contrast, proximity of photosynthetic tissue to major veins only appeared to mitigate the effects of water stress at the tips for broad lobes and not for tips of the lanceolate-shaped narrow lobes. Our findings indicate that the relationship between two-dimensional venation architecture and water delivery to leaf tissue may only partially 
Publisher: CSIRO; Journal: FP:Functional Plant Biology

Article Type: research-article; Volume: ; Issue: ; Article ID: FP13334

DOI: 10.1071/FP13334; TOC Head:

predict the location at which photosynthetic tissue will be most affected by water stress on a leaf

blade. We suggest that other anatomical features of these leaves, such as mesophyll thickness and the radial resistance of major veins, along with gross leaf morphology, are likely to be involved in determining the spatial pattern of leaf tissue hydration and associated physiological function.

\section{Acknowledgements}

We are grateful to Greg Jordan, Adrienne Nicotra and Brad Murray for helpful discussions and to two anonymous reviewers for comments on an earlier version of this manuscript. Thanks go to Wenfeng Ren for providing considerable help with anatomical work in this study. We thank the Australian Research Council for support (Discovery Project Grant DP110105380).

\section{References}

$<$ jrn>Barradas VL, Jones HG, Clark JA (1994) Stomatal responses to changing irradiance in Phaseolus vulgaris L. Journal of Experimental Botany 45, 931-936. doi:10.1093/jxb/45.7.931</jrn>

$<$ jrn>Blackman CJ, Brodribb TJ, Jordan GJ (2010) Leaf hydraulic vulnerability is related to conduit dimensions and drought resistance across a diverse range of woody angiosperms. New Phytologist 188, 1113-1123. doi:10.1111/j.1469-8137.2010.03439.x</jrn>

$<$ jrn>Blackman CJ, Brodribb TJ, Jordan GJ (2012) Leaf hydraulic vulnerability influences species' bioclimatic limits in a diverse group of woody angiosperms. Oecologia 168, 1-10. doi:10.1007/s00442-011-2064$\underline{3}</ \mathrm{jrn}>$

$<\mathrm{jrn}>$ Brodribb TJ, Cochard H (2009) Hydraulic failure defines the recovery and point of death in water-stressed conifers. Plant Physiology 149, 575-584. doi:10.1104/pp.108.129783</jrn>

$<$ jrn>Brodribb TJ, Holbrook NM (2005) Leaf physiology does not predict leaf habit; examples from tropical dry forest. Trees - Structure and Function 19, 290-295. doi:10.1007/s00468-004-0390-3</jrn>

$<$ jrn>Brodribb TJ, Feild TS, Jordan GJ (2007) Leaf maximum photosynthetic rate and venation are linked by hydraulics. Plant Physiology 144, 1890-1898. doi:10.1104/pp.107.101352</jrn>

$<$ jrn>Buckley TN, Mott KA (2000) Stomatal responses to non-local changes in PFD: evidence for long-distance hydraulic interactions. Plant, Cell \& Environment 23, 301-309. doi:10.1046/j.1365-3040.2000.00552.x</jrn>

<jrn>Cardon ZG, Mott KA, Berry JA (1994) Dynamics of patchy stomatal movements, and their contribution to steady state and oscillating stomatal conductance calculated using gas exchange techniques. Plant, Cell \& Environment 17, 995-1007. doi:10.1111/j.1365-3040.1994.tb02033.x</jrn>

<jrn>Cochard H, Nardini A, Coll L (2004) Hydraulic architecture of leaf blades: where is the main resistance? Plant, Cell \& Environment 27, 1257-1267. doi:10.1111/j.1365-3040.2004.01233.x</jrn>

$<$ jrn>Csintalan Z, Proctor MCF, Tuba Z (1999) Chlorophyll fluorescence during drying and rehydration in the mosses Rhytidiadelphus loreus (Hedw.) Warnst., Anomodon viticulosus (Hedw.) Hook. \& Tayl. and Grimmia pulvinata (Hedw.) Sm. Annals of Botany 84, 235-244. doi:10.1006/anbo.1999.0919</jrn> 
Publisher: CSIRO; Journal: FP:Functional Plant Biology

Article Type: research-article; Volume: ; Issue: ; Article ID: FP13334

DOI: 10.1071/FP13334; TOC Head:

<jrn>Deltoro VI, Calatayud A, Gimeno C, Barreno E (1998) Water relations, chlorophyll fluorescence, and membrane permeability during desiccation in bryophytes from xeric, mesic, and hydric environments. Canadian Journal of Botany 76, 1923-1929. doi:10.1139/b98-167</jrn>

<jrn>Demmig B, Winter K, Kruger A, Czygan FC (1988) Zeaxanthin and the heat dissipation of excess light energy in Nerium oleander exposed to a combination of high light and water-stress. Plant Physiology 87, 1724. doi:10.1104/pp.87.1.17</jrn>

<jrn>Iio A, Fukasawa H, Nose Y, Kakubari Y (2004) Stomatal closure induced by high vapor pressure deficit limited midday photosynthesis at the canopy top of Fagus crenata Blume on Naeba mountain in Japan. Trees - Structure and Function 18, 510-517.</jrn>

<jrn>Marenco RA, Siebke K, Farquhar GD, Ball MC (2006) Hydraulically based stomatal oscillations and stomatal patchiness in Gossypium hirsutum. Functional Plant Biology 33, 1103-1113.

doi:10.1071/FP06115 $</ j r n>$

<jrn>Meinzer FC, Goldstein G, Jackson P, Holbrook NM, Gutierrez MV, Cavelier J (1995) Environmental and physiological regulation of transpiration in tropical forest gap species - the influence of boundary layer and hydraulic properties. Oecologia 101, 514-522. doi:10.1007/BF00329432</jrn>

<jrn>Nicotra AB, Leigh A, Boyce CK, Jones CS, Niklas KJ, Royer DL, Tsukaya H (2011) The evolution and functional significance of leaf shape in the angiosperms. Functional Plant Biology 38, 535-552. doi:10.1071/FP11057</jrn>

<jrn>Omasa K, Takayama K (2003) Simultaneous measurement of stomatal conductance, non-photochemical quenching, and photochemical yield of photosystem II in intact leaves by thermal and chlorophyll fluorescence imaging. Plant \& Cell Physiology 44, 1290-1300. doi:10.1093/pcp/pcg165</jrn>

$<$ jrn>Sack L, Frole K (2006) Leaf structural diversity is related to hydraulic capacity in tropical rain forest trees. Ecology 87, 483-491. doi:10.1890/05-0710</jrn>

<jrn>Sack L, Tyree MT, Holbrook NM (2005) Leaf hydraulic architecture correlates with regeneration irradiance in tropical rainforest trees. New Phytologist 167, 403-413. doi:10.1111/j.1469$\underline{\text { 8137.2005.01432.x }}</ \mathrm{jrn}>$

<jrn>Scoffoni C, Rawls M, McKown A, Cochard H, Sack L (2011) Decline of leaf hydraulic conductance with dehydration: relationship to leaf size and venation architecture. Plant Physiology 156, 832-843. doi:10.1104/pp.111.173856</jrn>

<jrn>Siebke K, Weis E (1995) Assimilation images of leaves of Glechoma hederacea: analysis of nonsynchronous stomata related oscillations. Planta 196, 155-165. doi:10.1007/BF00193229</jrn>

<jrn>Sisó S, Camarero JJ, Gil-Pelegrin E (2001) Relationship between hydraulic resistance and leaf morphology in broadleaf Quercus species: a new interpretation of leaf lobation. Trees - Structure and Function 15, 341-345. doi:10.1007/s004680100110</jrn> 
Publisher: CSIRO; Journal: FP:Functional Plant Biology

Article Type: research-article; Volume: ; Issue: ; Article ID: FP13334

DOI: 10.1071/FP13334; TOC Head:

<jrn>Sommerville KE, Gimeno TE, Ball MC (2010) Primary nerve (vein) density influences spatial

heterogeneity of photosynthetic response to drought in two Acacia species. Functional Plant Biology 37 ,

840-848. doi:10.1071/FP10062</jrn>

<jrn>Sommerville KE, Sack L, Ball MC (2012) Hydraulic conductance of Acacia phyllodes (foliage) is driven by primary nerve (vein) conductance and density. Plant, Cell \& Environment 35, 158-168.

doi:10.1111/j.1365-3040.2011.02425.x </jrn>

<jrn>Tinoco-Ojanguren C, Pearcy RW (1993) Stomatal dynamics and its importance to carbon gain in 2 rainforest Piper species. 1. VPD effects on the transient stomatal response to lightflecks. Oecologia 94, 388394. doi:10.1007/BF00317114</jrn>

<jrn>Zhang SR, Ma KP, Chen LZ (2002) Tempo-spatial variations in stomatal conductance, aperture and density of Ligustrum sinense acclimated to different light environments. Acta Botanica Sinica 44, 12251232. $</ \mathrm{jrn}>$

<jrn>Zwieniecki MA, Melcher PJ, Boyce CK, Sack L, Holbrook NM (2002) Hydraulic architecture of leaf venation in Laurus nobilis L. Plant, Cell \& Environment 25, 1445-1450. doi:10.1046/j.1365$\underline{3040.2002 .00922 . x}</ j \mathrm{jn}>$

<jrn>Zwieniecki MA, Boyce CK, Holbrook NM (2004a) Functional design space of single-veined leaves: role of tissue hydraulic properties in constraining leaf size and shape. Annals of Botany 94, 507-513. doi:10.1093/aob/mch173</jrn>

<jrn>Zwieniecki MA, Boyce CK, Holbrook NM (2004b) Hydraulic limitations imposed by crown placement determine final size and shape of Quercus rubra L. leaves. Plant, Cell \& Environment 27, 357-365. doi:10.1111/j.1365-3040.2003.01153.x $</ j \mathrm{rn}>$

<jrn>Zwieniecki MA, Stone HA, Leigh A, Boyce CK, Holbrook NM (2006) Hydraulic design of pine needles: one-dimensional optimization for single-vein leaves. Plant, Cell \& Environment 29, 803-809. doi:10.1111/j.1365-3040.2005.01448.x</jrn>

Manuscript received 14 November 2013, accepted 25 February 2014

Fig. 1. Leaf shape variation in Lomatia tinctoria. The width of leaf lobes ranges from broad $(a)$ to narrow $(b)$. White bar represents $1 \mathrm{~cm}$.

Fig. 2. Image of the minor vein network of a narrow-lobed leaf of Lomatia tinctoria at $\times 100$ magnification. The radius of the largest circle that could fit within the largest areole was used to estimate the average distance between veins (the inverse of vein density).

Fig. 3. Chlorophyll fluorescence images of broad- and narrow-lobed leaves of Lomatia tinctoria immediately before $\left(\mathrm{T}_{\mathrm{dark}}\right.$ and $\left.\mathrm{T} 0 \mathrm{~L}_{\mathrm{ight}}\right)$, during (T20) and at the end (T40) of $40 \mathrm{~min}$ VPD-stress treatments. The two lefthand columns show quantum yield (maximum quantum yield, $F_{\mathrm{v}} / F_{\mathrm{m}}$, at $\mathrm{T} 0_{\text {dark }}$ and effective quantum yield, $\Delta F / F_{\mathrm{m}}{ }^{\prime}$, at $\mathrm{T} 0 \mathrm{~L}_{\mathrm{ight}}, \mathrm{T} 20$ and $\left.\mathrm{T} 40\right)$. The two right-hand columns show non-photochemical quenching (NPQ at T0 
$\mathrm{L}_{\text {ight, }}$ T20 and T40), with values divided by four to fit the scale. The false colour scale represents variation in fluorescence; the white bar in the first two images represents $1 \mathrm{~cm}$.

Fig. 4. Average vein distance and stomatal density at five positions on narrow-lobed (grey bars) and broadlobed (black bars) leaves of Lomatia tinctoria. Vein distance was calculated as the radius of the largest circle that could be placed within the minor vein areoles (see Fig. 2) and its inverse is referred to as vein density in text. Data presented graphically are untransformed. Averages \pm s.e. are shown.

Fig. 5. Comparison of ( $a$ ) effective quantum yield $\left(\Delta F / F_{\mathrm{m}}{ }^{\prime}\right)$ and $(b)$ non-photochemical quenching (NPQ) between broad-lobed (black bars) and narrow-lobed (grey bars) Lomatia tinctoria leaves before (T0 $\mathrm{L}_{\mathrm{ight}}$ ), during (T20) and at the end of 40 min vapour pressure deficit-stress treatments (T40). Data presented graphically are untransformed. Averages \pm s.e. are shown.

Table 1. Summary of two-way ANOVA tests for differences in average vein distance (inverse of vein density, see Fig. 2$)$, stomatal density and maximum quantum yield $\left(F_{\mathrm{v}} / F_{\mathrm{m}}\right)$ between two different leaf morphs (broad and narrow) and among four positions on the lamina (tip, centre, edge and base of lobe) in Lomatia tinctoria

Data for stomatal density were log-transformed. All interactions between morph and position were non-significant and are not reported here. The directions of significant effects of morph or position were determined post hoc $(\alpha=0.05)$ and are indicated with arrows

\begin{tabular}{lcccc}
\hline Variable & Morph & Morph effects & Position & Position effects \\
\hline $\begin{array}{l}\text { Average vein } \\
\text { distance }\end{array}$ & $\mathrm{F}_{(7,32)}=44.5$ & Broad $>$ narrow & $\mathrm{F}_{(7,32)}=7.37$ & Tip $<$ centre \\
& $(P<0.000)$ & & $(P=0.001)$ & Tip $<$ base \\
$\begin{array}{l}\text { Stomatal } \\
\text { density }\end{array}$ & $\mathrm{F}_{(7,32)}=0.23$ & - & $\mathrm{F}_{(7,32)}=0.60$ & - \\
& & & $(P=0.620)$ & - \\
$F_{\mathrm{v}} / F_{\mathrm{m}}$ & $(P=0.638)$ & & $\mathrm{F}_{(7,24)}=0.37$ & \\
& $\mathrm{~F}_{(7,24)}=13.3$ & Broad $<$ narrow & $(P=0.776)$ & \\
\hline
\end{tabular}

Table 2. Summary of repeated-measures ANOVA tests for differences in effective quantum yield $\left(\Delta F / F_{\mathrm{m}}\right)$ and non-photochemical quenching (NPQ) between two different Lomatia tinctoria leaf morphs (broad and narrow) among four positions on the lamina (tip, centre, edge and base of lobe) before, during and after VPD-stress treatments: T0 (immediately before stress), T20 and T40 (20 and $40 \mathrm{~min}$ after the onset of stress respectively)

Analyses were performed on arcsine transformed $\Delta F / F_{\mathrm{m}}{ }^{\prime}$ data and log-transformed NPQ data

\begin{tabular}{lcccc}
\hline Variable & Time & Time $\times$ morph & Position & Position $\times$ morph \\
\hline$\Delta F / F_{\mathrm{m}^{\prime}}$ & $\mathrm{F}_{(2,12)}=9.22$ & $\mathrm{~F}_{(2,12)}=0.39$ & $\mathrm{~F}_{(3,18)}=21.2$ & $\mathrm{~F}_{(3,18)}=3.98$ \\
& $(P=0.004)$ & $(P=0.684)$ & $(P<0.000)$ & $(P=0.024)$ \\
NPQ & $\mathrm{F}_{(2,12)}=19.2$ & $\mathrm{~F}_{(2,12)}=0.17$ & $\mathrm{~F}_{(1.5,8.8)}=6.82$ & $\mathrm{~F}_{(1.5,8.8)}=0.12$ \\
& $P<0.000$ & $P=0.845$ & $P=0.021^{\mathrm{A}}$ & $P=0.832^{\mathrm{A}}$ \\
\hline
\end{tabular}

${ }^{\mathrm{A}}$ Greenhouse-Geisser test used as data did not meet Mauchly's assumptions of sphericity.

Table 3. Results of two-way ANOVA tests for differences in effective quantum yield $\left(\Delta F / F_{m}{ }^{\prime}\right)$ and non-photochemical quenching (NPQ) among four positions on the lamina (tip, centre, edge and base of lobe) before, during and after VPD-stress treatments: T0 (immediately prior stress), T20 and T40 (20 and $40 \mathrm{~min}$ after the onset of stress respectively)

To investigate how variation in position differed between morphs, analyses were here conducted for each morph separately. Analyses were performed on arcsine transformed $\Delta F / F_{\mathrm{m}}{ }^{\prime}$ data and log- 
Publisher: CSIRO; Journal: FP:Functional Plant Biology

Article Type: research-article; Volume: ; Issue: ; Article ID: FP13334

DOI: 10.1071/FP13334; TOC Head:

transformed NPQ data. The directions of significant effects of time and position were determined post

$$
\text { hoc }(\alpha=0.05) \text { and are indicated with arrows }
$$

\begin{tabular}{|c|c|c|c|c|}
\hline Morph & Time & Time effects & Position & Position effects \\
\hline \multicolumn{5}{|c|}{$\Delta F / F_{\mathrm{m}}^{\prime}$} \\
\hline Broad & $\begin{array}{l}\mathrm{F}_{(2,6)}=14.9 \\
(P=0.005)\end{array}$ & $\begin{array}{c}\mathrm{T} 0>\mathrm{T} 40 \\
\mathrm{~T} 20>\mathrm{T} 40\end{array}$ & $\begin{array}{l}\mathrm{F}_{(3,9)}=4.16 \\
(P=0.042)\end{array}$ & Edge $<$ base \\
\hline Narrow & $\begin{array}{l}\mathrm{F}_{(2,6)}=3.34 \\
(P=0.106)\end{array}$ & - & $\begin{array}{l}\mathrm{F}_{(3,9)}=18.6 \\
(P<0.000)\end{array}$ & $\begin{array}{c}\text { Tip }<\text { edge } \\
\text { Tip }<\text { centre } \\
\text { Tip }<\text { base }\end{array}$ \\
\hline Broad & $\begin{array}{l}\mathrm{F}_{(2,6)}=34.1 \\
(P=0.001)\end{array}$ & $\begin{array}{r}\mathrm{NP} \\
\mathrm{T} 0<\mathrm{T} 20<\mathrm{T} 40\end{array}$ & $\begin{array}{l}\mathrm{F}_{(3,9)}=11.1 \\
(P=0.002)\end{array}$ & $\begin{array}{c}\text { Tip }>\text { centre } \\
\text { Tip }>\text { base } \\
\text { Edge }>\text { base }\end{array}$ \\
\hline Narrow & $\begin{array}{l}\mathrm{F}_{(2,6)}=5.49 \\
(P=0.044)\end{array}$ & $\mathrm{T} 0<\mathrm{T} 40$ & $\begin{array}{l}\mathrm{F}_{(3,9)}=2.38 \\
(P=0.137)\end{array}$ & - \\
\hline
\end{tabular}

Table 4. Summary of repeated-measures ANOVA tests for differences in leaf temperature, stomatal conductance $\left(g_{\mathrm{s}}\right)$ and instantaneous water use efficiency (WUE: photosynthetic rate/transpiration rate) between two different Lomatia tinctoria leaf morphs (broad and narrow) at the onset and end of VPD-stress treatments

Values for each variable for the start and end of treatments were based on an average of the first three measurements from when VPD reached $3 \mathrm{kPa}$ and the last three measurements of each treatment, respectively. All data met Mauchly's assumptions of sphericity

\begin{tabular}{lcc}
\hline Variable & Morph & Morph $\times$ time \\
\hline Leaf temperature & $\mathrm{F}_{(1,6)}=0.55$ & $\mathrm{~F}_{(1,6)}=0.47$ \\
& $P=0.487$ & $P=0.519$ \\
$g_{\text {s }}$ & $\mathrm{F}_{(1,6)}=0.34$ & $\mathrm{~F}_{(1,6)}=0.038$ \\
WUE & $P=0.583$ & $P=0.852$ \\
& $\mathrm{~F}_{(1,6)}=0.75$ & $\mathrm{~F}_{(1,6)}=0.66$ \\
& $P=0.419$ & $P=0.448$ \\
\hline
\end{tabular}

